\title{
It's a Long Way to the Top: Women's Ministerial Career Paths
}

\section{Corinna Kroeber (iD}

\section{University of Greifswald}

\section{Joanna Hüffelmann}

\section{University of Greifswald}

Ministerial portfolios that promise high status, broad public visibility, and extensive financial and personnel resources continue to be men's domains. In this article, we shed light on gender inequality in ministerial selection processes by studying the duration from a minister's original appointment as a member of cabinet until he or she receives responsibility for a highly prestigious portfolio. We argue that the time it takes for ambitious politicians to prove themselves suitable for this type of cabinet position depends on their sex and the degree to which the policy area for which they are responsible reinforces stereotypical expectations about their personality traits. Empirical evidence from event history analysis of original data including detailed information on all ministerial careers in 27 European countries between 1990 to 2018 supports these propositions. These findings reveal that even highly qualified women politicians who are already members of the executive face additional barriers during their political careers.

Keywords: Executives, gender, women, ministerial selection, political careers, portfolio allocation

$\not$ ven though women's overall proportions in the governments 1 of developed democracies have increased considerably over the last few decades, women ministers in charge of the most prestigious (i.e., pivotal, resourceful, and visible) positions still remain an exception.

Both authors contributed equally to this work. We would like to thank two students in the course "Current Research in Political Behavior" at the University of Konstanz for helpful comments on an earlier version of this manuscript, as well as three anonymous reviewers for their very valuable, insightful, and constructive comments on this article.

(c) The Author(s), 2021. Published by Cambridge University Press on behalf of the Women, Gender, and Politics Research Section of the American Political Science Association. This is an Open Access article, distributed under the terms of the Creative Commons Attribution licence (http://creativecommons.org/licenses/by/4.0/), which permits unrestricted re-use, distribution, and reproduction in any medium, provided the original work is properly cited. doi:10.1017/S1743923X21000118 
While most women receive responsibility for portfolios such as family or social affairs, health, or justice, very few receive responsibility for ministerial portfolios such as finance, economy, interior, or foreign affairs (Escobar-Lemmon and Taylor-Robinson 2009; Goddard 2019a; Krook and O'Brien 2012). If women make it to the top, their way to the most prestigious executive positions appears to be particularly long: Brigitte Zypries (Germany) served as minister of justice for seven years before becoming minister of economy; Paula Risikko (Finland) occupied various government positions as minister of environment, social affairs, and transport over a span of eight years before she received the ministry of interior; and Marie-Josée Jacobs (Luxembourg) was in charge of portfolios such as family, integration, and humanitarian affairs for a total of 15 years before being selected as minister of international cooperation. While extensive scholarly work has studied the portfolios that male and female ministers tend to receive, systematic differences in the duration of their ministerial career stages has not yet received any attention in the literature. In this article, we aim to answer the following research question: How does a minister's sex impact his or her career path to joining the cabinet for the first time?

We argue that female ministers have to serve longer in less prestigious executive positions before getting to the top. Our proposition is that, even after being selected as a member of the cabinet, gatekeepers for ministerial positions hold prejudices about women's competence to be responsible for certain portfolios, and to overcome them, women have to demonstrate their capabilities more extensively (Kenney 1996, 458) or gather exceptionally high levels of experience compared with their male colleagues. It is only after female ministers have spent additional time in secondary cabinet positions that they will be considered viable candidates for more prestigious executive offices. In addition to this direct link between minister's sex and ministerial career patterns, we propose that holding portfolios strongly associated with feminine stereotypes reinforces doubts about aspirants' capacity to carry out responsibility for the most prestigious portfolios - not only for female ministers. The tendency to assign female ministers to feminine portfolios, though, should create a double barrier for women on their way to the top, and their run-up will have to be longer to overcome these additional hurdles.

To open the black box of intra-cabinet promotion processes, we make use of an original data set containing information on the career paths of all ministers in 27 European countries between 1990 and 2018. Most notably, these data include a count variable that indicates the number of 
months a person served in low- and medium-prestige offices before either proceeding to a more prestigious position or leaving the cabinet. Based on this information, we apply survival analysis to predict the chances to and duration until ministers receive a highly prestigious portfolio. Our key explanatory variables are the minister's sex, the definition of the portfolio as associated with stereotypically feminine, neutral, or masculine traits (Escobar-Lemmon and Taylor-Robinson 2009; Goddard 2019a; Krook and O'Brien 2012), and the interaction of the two variables.

The empirical evidence reveals that, even after original selection to the cabinet, ministerial career paths continue to be gendered: male ministers tend to receive the most resourceful and influential portfolios, either without previous executive experience or shortly after being selected to the cabinet, while their female colleagues have to wait considerably longer to get to the top. Responsibility for portfolios traditionally ascribed to women's role in society also hinders ministers' ascent to top positions, for both male and female ministers. Nevertheless, we find no evidence that women holding feminine portfolios such as family, children, elderly, health, or social affairs face additional barriers compared with men. These findings contribute to the growing body of scholarly work engaging with women's recruitment to cabinet positions (Annesley et al. 2019; Costa Pinto and Tavares de Almeida 2009; Escobar-Lemmon and Taylor-Robinson 2009; Goddard 2019a; Krook and O'Brien 2012; Verge and Claveria 2017; Verge and de la Fuente 2014) by showing that gender inequalities persist even within this highly selective group of ministers. Furthermore, our findings suggest that the portfolios that female ministers are most likely to receive are valued least by gatekeepers. Such feminine ministries are poor career stepping stones for ministers of both sexes - but the risk of ending up in a dead end on the ministerial career path is considerably higher for women than for men.

\section{MINISTERIAL CAREER PATHS: THE IMPORTANCE OF GENDER AND PRESTIGE}

The literature engaging with ministers' career paths addresses three main topics: (1) the recruitment process (how do ministers get there?), (2) portfolio allocation (which positions do they receive?), and (3) survival (how long do they stay there?). ${ }^{1}$ Scholarly work identifies disadvantages

1. Beyond studying careers in office, some studies also address postministerial careers (e.g., Baturo 2017; Claveria and Verge 2015; Dörrenbächer 2016). 
for women in all three categories, albeit to a decreasing extent in recent years (e.g., Escobar-Lemmon and Taylor-Robinson 2009; Goddard 2019a).

Access to ministerial careers is highly restrictive. Party leaders and heads of government serve as gatekeepers who try to identify suitable aspirants (cf. Bright, Döring, and Little 2015; Goddard 2019a, 634; Kerby and Snagovsky 2019, 6). Beyond the candidates' political competencies and views (Huber and Martinez-Gallardo 2008), loyalty toward the party leadership plays a crucial role in the ex ante screening processes to avoid policy conflicts and alliances against gatekeepers (Goddard 2019a, 634). Trust, which develops gradually over time through membership in inner circles of power and closed networks, is therefore a key proposition for ministerial selection (Annesley, Beckwith, and Franceschet 2019, 133, 153-54; Costa Pinto and Tavares de Almeida 2009, 154-55; Verge and Claveria 2017, 92, 94; Verge and de la Fuente 2014, 73).

The intensity of screening procedures varies with the importance of the portfolio for which an aspirant is being considered. Candidates in highly prestigious positions tend to be selected with particular caution, since poor choices would receive additional public attention and are more likely to put the gatekeepers' political fortunes at risk (Bright, Döring, and Little 2015, 5; Huber and Martinez-Gallardo 2008) - making these portfolios pivotal for cabinet governance.

A portfolio's level of prestige is a consequence of a multitude of factors (Barnes and O'Brien 2018; Escobar-Lemmon and Taylor-Robinson 2005; Goddard 2019a; Krook and O’Brien 2012, 842), including available resources, policy impact, and potential as a career stepping stone. First of all, portfolios vary regarding the resources that are at the minister's disposal - for instance, budget share, number of employees, and publicity, but also recognition by voters. Furthermore, the degree to which a minister is allowed to shape public policy and provide direct access to the head of government's inner circle of power determines a portfolio's position in the internal hierarchy of ministerial offices. Lastly, the way a portfolio shapes the minister's career prospects for future political offices distinguishes portfolios by levels of prestige.

Summing up these considerations, portfolios such as defense, finance, economy, foreign affairs, and interior usually qualify as highly prestigious (Goddard 2019a; Krook and O'Brien 2012). Portfolios with a medium level of prestige have considerable financial resources but less status and public attention. This category includes portfolios such as agriculture, education, and justice. The least prestigious positions have few resources and include policy areas such as culture and tourism (Krook and O'Brien 2012, 844). 
Previous research indicates that ministers' chances of staying in office are closely linked to the prestige of their portfolios. Bright, Döring, and Little $(2015,10)$ find evidence that incumbents of ministerial portfolios with high status stay longer in government than those with less reputable positions (see also Berlinski, Dewan, and Dowding 2007). Hence, there are long-term career advantages for those who overcome the additional barriers to selection to a highly prestigious post. For those aspiring to such an office, however, the low fluctuation in officeholders makes achieving this endeavor even more difficult.

Overall, female aspirants are still less likely to be selected as ministers. However, the gender gap in cabinet nominations has been decreasing in most countries around the world - albeit to different degrees and at different paces (Barnes and Taylor-Robinson 2018; Claveria 2014; YuvalDavis 1997). As an explanation for the low share of female ministers, researchers have argued that the recruitment process is biased against women in at least two ways: first, traditional roles ascribed to women as caretakers at home lead to prejudice about their qualifications for government positions and, second, women's lack of access to high-trust networks decreases their chances of proving themselves as reliable allies.

The first systematic barrier that women face when aspiring to enter government office is stereotypical thinking - beliefs based on stylized expectations of individuals' traits and capabilities as a result of their sex (e.g., Broverman et al. 1972). As a constantly growing set of contributions indicates, stylized expectations influence party gatekeepers' decisions during selection (Annesley, Beckwith, and Franceschet 2019, 18; Barnes and O'Brien 2018; Burrell 1994; Goddard 2019a; Rosenwasser and Dean 1989). ${ }^{2}$ Stereotyping originates from belief systems that ascribe different roles in society to men and women based on their sex. It leads to expectations concerning the tasks that each sex ought to fulfill and their individual characteristics. During this process, gatekeepers first ascribe to women and men certain substantive expertise and then distinct leadership styles. Being warm, servile, emotional, and sensitive is perceived as stereotypically female, while being decisive, aggressive, independent, active, and logical characterizes stereotypically male behavior (Eagly and Mladinic 1989, 547; Hoffman and Hurst

2. Studies taking approaches other than principal-agent theory indicate that variation in women's chances of entering the executive is a consequence of the scarcity of available offices (Barnes and Taylor-Robinson 2018), institutional and cultural factors (Jalalzai 2008), coalition agreements (Krook and O'Brien 2012), the ideological composition of the government (Siaroff 2000), and gender equality and societal structure (Arriola and Johnson 2014). 
1990). These traits are connected to social norms that assign men the responsibility for the public sphere, while women are in charge of the private sector (Eagly and Mladinic 1994; Hoffman and Hurst 1990; Krook and O'Brien 2012, 842).

Following this rationale, typical women's tasks include child care and family work, while men are the breadwinners (Hoffman and Hurst 1990, 197). Originally, researchers used stereotyping to explain why men are generally perceived to be more competent and knowledgeable than women in conducting leadership tasks and in running politics (Carli 2001; Eagly and Karau 2002; Schneider and Bos 2014), and thus why fewer women are selected to political positions. However, the growing number of women in the executive implies that the influence of this aspect of stereotyping at the entry point to any ministerial office is declining. Static roles changed as women entered the public sphere, but stereotypes about men's and women's competencies are still directly related to attitudes about them (Eagly et al. 2020).

Notably, traditional views of gender roles and the division of labor between the public and private spheres still shape the portfolios that female politicians tend to receive. Policy areas such as economy and finance are associated with supposedly inherently masculine traits, ${ }^{3}$ while family, youth, social affairs, and health are supposed to be more compatible with feminine traits (Goddard 2019a; Krook and O'Brien 2012). Moreover, since party gatekeepers expect that women have more expertise in some fields than others, they mostly entrust female politicians with a limited set of feminine areas of responsibility (EscobarLemmon and Taylor-Robinson 2009, 690; Goddard 2019a, 637). Even if a woman receives what might be labeled a masculine portfolio, she is significantly less likely than her male colleagues to switch from one of these to another portfolio (Escobar-Lemmon and Taylor-Robinson 2009, 691).

Beyond stereotypical thinking, women struggle with their absence from party gatekeepers' inner circles and the resulting difficulty of distinguishing themselves as reliable party agents: high-trust networks continue to be open mainly to men (Annesley, Beckwith, and Franceschet 2019, 29; Annesley and Gains 2010, 463; Franceschet and Piscopo 2014, 89; Niven 1998, 61, 72; Verge and Claveria 2017, 92, 94). Entering them is harder for women than for men because they form during exclusive social activities and events

3. The rising number of female defense ministers is attributable to a policy tendency toward peacekeeping missions, rather than a change in stereotypical thinking (Barnes and O'Brien 2018). 
to which women often do not have access (Annesley, Beckwith, and Franceschet 2019, 29; Goddard 2019a, 634). Andrea Nahles, former leader of the German Social Democratic Party, said in a media interview that it is nearly impossible for a woman to become part of networks of men in politics (Rüdel 2019). Given that gatekeepers require a particularly high level of trustworthiness from candidates for the most prestigious posts, the lack of close connections between female aspirants and male selectors likely results in doubts concerning women's loyalty and a lower likelihood of being appointed to the most important executive offices (Goddard 2019a; Krook and O’Brien 2012). ${ }^{4}$

We argue that there are not only different chances for men and women to reach prestigious positions, but also the pathway to reaching these portfolios is gendered. By studying the duration from a minister entering the cabinet for the first time until receiving a highly prestigious portfolio (or leaving the cabinet without succeeding in doing so), we can reveal the extent to which women's journey to the top is more demanding than men's. This research interest is shaped by the assumption that ministers display progressive ambitions (Schlesinger 1966) - that is, they aspire to a more prestigious office. While female citizens are known to display lower levels of political ambition in general (Lawless 2012), the fact that men and women have rather similar postministerial careers (Claveria and Verge 2015) suggests that ministers are a unique group of actors with negligible sex difference in political ambition. Therefore, we build on the expectation that politically successful women who receive a ministry reach even higher and have similar career aims as their male colleagues. Based on this proposition, we formulate three expectations.

To begin with, we hypothesize that a minister's sex influences the amount of time he or she remains in a less prestigious position before reaching a prestigious portfolio. This pattern could be the consequence of two processes that are not mutually exclusive: first, during long periods in less prestigious portfolios, female ministers could prove to gatekeepers that they are sufficiently qualified and reliable. Previous research indicates that, because of the match between stereotypes about successful high-profile politicians and their gender, male ministers should be expected to be competent, even if they are not equipped with any

4. All ministries that are ranked highest on status fall into the masculine categorization (Krook and O'Brien 2012). It is important to notice that not all masculine ministries are prestigious agriculture and labor, for example, are defined as medium-prestige portfolios, while science and technology are low-prestige portfolios (Goddard 2019a; Krook and O'Brien 2012; for an overview, see Table 1). 
relevant experience for the job (Schneider and Bos 2014, 259). Doubts about women's capacity to be in charge of a high-profile portfolio, in turn, will be more pronounced. Women will have to demonstrate their skills in various situations before being entrusted with high-ranking positions (Kenney 1996, 458). Research comparing the careers of male and female executives found similar patterns, showing that women have to fulfill higher numbers of nonauthoritative tasks before getting to the top (Lyness and Thompson 2000). According to this rationale, it should take longer until gatekeepers are convinced that a female aspirant is sufficiently qualified to take over responsibility for a highly prestigious position.

During their time in less prestigious portfolios, female ministers could gather additional experience as members of the executive. Research indicates that women's political career profiles are exceptional. For instance, several studies indicate that female ministers and prime ministers tend to have higher levels of education and experience in other political offices compared with men (Franceschet and Piscopo 2012; Jalalzai 2013, 81-82; Müller-Rommel and Vercesi 2017; Verge and Astudillo 2018). Furthermore, to survive in office, female party leaders have to be more successful in elections than their male colleagues (O'Brien 2015). In this sense, longer duration in less prestigious positions constitutes another exceptional qualification that gatekeepers might demand from female but not male aspirants for prestigious executive positions.

Even though female ministers in charge of less prestigious portfolios likely remain outside of the powerful male-dominated networks that form during exclusive social events, the perception of these women by selectors is likely to change the longer they serve in low- or mediumprestige portfolios. By proving that they are capable of leading a ministry and by gathering exceptionally high levels of experience as members of the cabinet, the chances that female ministers will be perceived as viable candidates for the most prestigious portfolios increases.

$\boldsymbol{H}_{\boldsymbol{l}} \quad$ Female ministers stay longer in low- and medium-prestige portfolios before ascending to high-prestige offices than male ministers.

Second, we propose that the gendered nature of the portfolio held by a minister might be just as decisive for the time until promotion to a highly prestigious position as the minister's sex. Again, stereotypes and access to influential networks provide explanations for this pattern. To begin with, gatekeepers might develop prejudice about a minister's capabilities as a 
consequence of the position the person holds. Feminine portfolios are typically associated with "soft" issues, as opposed to "hard," masculine ones (Escobar-Lemmon and Taylor-Robinson 2009, 687). Stereotypes deduced from a minister's responsibilities might overshadow beliefs based on his or her sex, depriving the ministers in feminine ministries of the necessary hard skills for prestigious masculine ministries. Moreover, previous research indicates that feminine ministries are bad stepping stones for those trying to move to positions with a high level of reputation because of their exclusion from powerful networks (EscobarLemmon and Taylor-Robinson 2009, 693). Compared with masculine portfolios, there is low "upward mobility" (Escobar-Lemmon and TaylorRobinson 2009, 693) in feminine portfolios, as they do not function as a recruitment ground (Escobar-Lemmon and Taylor-Robinson 2009, 687). They provide little resources, personnel, and media attention - all factors that enhance ministerial careers. Further, the leaders of feminine portfolios receive little attention in cabinet meetings, which often focus on high-budget projects, so their visibility within the cabinet is limited as well (Verge and de la Fuente 2014, 72). This lack of access to the principal's direct network makes it harder for ministers in charge of feminine portfolios to demonstrate their intentions and capabilities for more prominent positions. Following these rationales, we expect the following:

$\mathrm{H}_{2}$ Ministers who have held a feminine portfolio stay longer in lowand medium-prestige portfolios before ascending to high-prestige offices than ministers who have never held a feminine portfolio.

Lastly, we hypothesize that women holding feminine portfolios face an additional barrier to recruitment to highly prestigious positions. The dilemma is that female politicians holding feminine portfolios confirm stereotypes. Women who serve as minister of health or women's affairs fulfill the expectations that follow from traditional role models, and hence they might reaffirm the proposition that they are not sufficiently prepared to serve in masculine, highly prestigious positions. Looking at legislatures, Franceschet, Krook, and Piscopo $(2012$, 238) show that the substantively expected social policy focus of female legislators binds them to secondary status in the Brazilian Congress. Further, EscobarLemmon and Taylor-Robinson's (2009, 691) findings indicate that women rarely change from a feminine to a masculine domain. By contrast, men do not have to (re)demonstrate masculine stereotypes, making it easier for them to be considered for prestigious positions even 
if they have held a feminine portfolio. ${ }^{5}$ These considerations lead us to our final hypothesis:

$\mathrm{H}_{3} \quad$ Female ministers who have held a feminine portfolio stay longer in low- and medium-prestige portfolios before ascending to high-prestige offices than male ministers who have held a feminine portfolio.

\section{CASE SELECTION AND OPERATIONALIZATION}

Our data cover 27 European countries between 1990 to 2018, including Austria, Belgium, Bulgaria, Czech Republic, Denmark, Estonia, Finland, France, Germany, Greece, Hungary, Iceland, Ireland, Italy, Latvia, Lithuania, Luxembourg, Netherlands, Norway, Poland, Portugal, Romania, Slovakia, Slovenia, Spain, Sweden, and the United Kingdom. The country sample covers the same cases as the European Representative Democracy Data Archive (Andersson, Bergman, and Ersson 2014), and therefore it includes cases frequently used in comparative research studying governments. The country choice balances concerns about external and internal validity. On the one hand, the observations differ considerably with regard to the inclusion of women in politics as key factor, but also when it comes to confounding variables such as institutional design, which allows the findings to be generalized from the sample to other established industrial democracies. On the other hand, limiting the sample to broadly comparable countries ensures a certain level of contextual homogeneity that makes us confident that we are able to capture all confounding variables. The time frame of our analyses starts in 1990 and ends in 2018, covering the decades during which women's presence in executives around the worlds started to increase significantly (Franceschet, Krook, and Tan 2019).

We gathered a full list including all ministers per government, their portfolios, and the time each minister remained in a given position. ${ }^{6} \mathrm{We}$ reorganized this information so that individual ministers constitute our unit of analysis. The data set covers a total of 4,548 observations.

5. While female ministers have a considerably higher probability of serving in feminine portfolios during their executive careers than male ministers, our data still include a large number of men in charge of these portfolios. This pattern is a consequence of men's sheer overrepresentation in governments and allows us to study the interaction between the minister's sex and the gendered nature of portfolios empirically without facing collinearity problems.

6. We retrieved this list from http://www.kolumbus.fi/taglarsson and excluded all heads of government and deputy heads of government without portfolios. 


\section{Dependent Variable: Time to Reach a Highly Prestigious Office}

Our dependent variable includes two pieces of information: whether a minister ever received a prestigious portfolio, and if so, how many months this person served in less prestigious positions beforehand. We focus on portfolio allocation instead of ministries, as ministers might be responsible for more than one portfolio within a single ministry, which can represent different levels of prestige.

The first piece of information is provided as a dummy variable that takes a value of 1 if a minister received responsibility for a highly prestigious portfolio during the course of his or her career and 0 if not. To create this variable, we build on a coding scheme by Krook and O'Brien (2012) that assigns portfolios to levels of prestige. ${ }^{7}$ Since our data include additional portfolios, and to ensure that these cases can be included in the analyses, we added several portfolios to the coding scheme. In doing so, we followed the rationale of the original coding, which identifies portfolios with a low level of prestige as those lacking resources for patronage, those with a medium level of prestige as those with significant financial resources but limited status and visibility, and those with a high level of prestige as those with visibility and control over policy (Krook and O'Brien 2012, 845). Several portfolios, such as administration, commerce and industry, European affairs, and international trade, have only limited status but share control over policy with highly prestigious portfolios such as economy or foreign affairs. We code these cases as "high prestige" to account for their policy impact. ${ }^{8}$ Table 1 shows the coding based on the list of portfolios by level of prestige.

The second piece of information is a count variable that identifies the number of months a person served in any other office before reaching a highly prestigious position for the first time or leaving the cabinet without ever receiving such a position. We start with the first ministerial appointment and count the number of months until a person either is assigned responsibility for a highly prestigious position or leaves the

7. While we acknowledge variation in the level of prestige of certain portfolios within and between countries (Escobar-Lemmon and Taylor-Robinson 2016; Warwick and Druckman 2006), the categorization captures the relative importance of different ministries across different contexts (Krook and O'Brien 2012, 845).

8. Such an expansive operationalization of prestige increases the number of women reaching highly prestigious positions and decreases the likelihood of finding significant effects of the minister's sex and the gendered nature of portfolios. In this sense, our coding leads to conservative estimates concerning the effects of these variables. Nevertheless, we provide a robustness test for which we coded only the core ministries introduced by Krook and O’Brien (2012) as highly prestigious (see Appendix 6, Test 9). 
Table 1. Coding of portfolios by level of prestige and assignment to stereotypically masculine, feminine, and neutral traits

\begin{tabular}{|c|c|c|c|c|}
\hline Coding & $\begin{array}{l}\text { Level of } \\
\text { Prestige }\end{array}$ & Masculine & Feminine & Neutral \\
\hline $\begin{array}{l}\text { High prestige } \\
\text { (1) }\end{array}$ & & $\begin{array}{l}\text { administration, commerce and industry, } \\
\text { defense, economy, enterprise, European } \\
\text { affairs, finance, foreign affairs, interior, } \\
\text { international cooperation, international } \\
\text { trade, public security }\end{array}$ & & \\
\hline \multirow[t]{2}{*}{$\begin{array}{l}\text { Medium and } \\
\text { low } \\
\text { prestige }(0)\end{array}$} & $\begin{array}{l}\text { Medium } \\
\text { prestige }\end{array}$ & $\begin{array}{l}\text { agriculture, construction and public work, } \\
\text { employment, fishery, food, forestry, } \\
\text { information and communication, } \\
\text { infrastructure, religious affairs, } \\
\text { transportation }\end{array}$ & $\begin{array}{l}\text { education, health, } \\
\text { social affairs, } \\
\text { welfare }\end{array}$ & $\begin{array}{l}\text { climate, consumer protection, energy, } \\
\text { environment, housing, justice, } \\
\text { natural resources, planning and } \\
\text { development, public service and civil } \\
\text { service, sustainable development }\end{array}$ \\
\hline & $\begin{array}{l}\text { Low } \\
\text { prestige }\end{array}$ & science, technology & $\begin{array}{l}\text { children, culture, } \\
\text { elderly, equality, } \\
\text { family, women, } \\
\text { youth }\end{array}$ & $\begin{array}{l}\text { constitutional and institutional affairs, } \\
\text { development aid, development } \\
\text { cooperation, expatriates, immigration, } \\
\text { international development, minority } \\
\text { affairs, regional affairs, sports, tourism }\end{array}$ \\
\hline
\end{tabular}

Notes: Italics indicate that the authors added a portfolio to the list. Appendix 1 includes a detailed list of all portfolios summarized under each term. Source: Authors' depiction based on Krook and O’Brien (2012). 
government. ${ }^{9}$ If a person was not part of the government in between, we subtract the number of months out of office from our variable.

Overall, 1,912 ministers (42.04\%) reached a prestigious position. Ministers remained between 1 and 180 months in less prestigious positions before either ascending to top executive posts or leaving the executive. On average, a career in less prestigious positions lasts 18.85 months. ${ }^{10}$ The two variables have a negative correlation $(-0.48$, $p<.001$ ), suggesting that people who served long periods as minister of a less prominent portfolio have lower chances of receiving one of the most attractive positions.

\section{Explanatory Variables: Minister’s Sex and Portfolio Responsibilities}

Our explanatory variables include the minister's sex, the gendered nature of the portfolio, and the interaction of the two variables. The sex of ministers is coded 1 for women and 0 for men. For that purpose, we hand-coded the sex of all ministers. We relied on three resources: language skills if a name is clearly associated with a sex, the European Journal of Political Research's Political Data Yearbook (1992-2002), ${ }^{11}$ and texts or photos on government websites or in the news.

To identify the gendered nature of the portfolio, we include a dummy variable indicating whether a person ever held a feminine portfolio. We identified this information based on the coding of feminine, masculine, and neutral portfolios by Krook and O'Brien (2012) as presented in Table 1.

Our sample includes 932 female (20.49\%) and 3,616 male (79.51\%) ministers. Only 1,104 ministers $(24.27 \%)$ were in charge of a feminine portfolio at some point during their executive career. In accordance with the literature (Escobar-Lemmon and Taylor-Robinson 2009; Goddard 2019a; Krook and O’Brien 2012), we find that female ministers are twice as likely to hold feminine portfolios as male ministers $(46.46 \%$ versus 23.48\%). Nevertheless, the correlation between the two variables is relatively low at 0.21 , allowing us to include both of them in one model without causing multicollinearity problems.

9. Note that event history analysis excludes observations for which the time period is zero. We therefore coded all ministers who served zero month in less prestigious positions (i.e., where immediately selected to highly prestigious positions) as ' 1 ' month in office before selection to a highly prestigious position. As a robustness test, we calculated additional models excluding these cases from the analysis (see Appendix 4 and 5, Test 2).

10. Overall, an average ministerial career lasts 27.61 months, with a minimum of $l$ and a maximum of 213 months.

11. Available at https://ejpr.onlinelibrary.wiley.com/hub/journal/20478852/homepage/germany.htm. 


\section{Control Variables}

Our research design takes into account confounding variables that are known to influence women's chances of getting into highly prestigious positions. First of all, the literature engaging with gender differences in ministerial selection emphasizes the importance of the sex of the head of government (HoG), although empirical evidence concerning the relevance of this factor is mixed. On the one hand, researchers found support for the assumption that female leaders prefer and support female aspirants for highly prestigious positions (Franceschet 2016; Jalalzai 2019). On the other hand, others observed no effect of the sex of HoGs on women's chances of being nominated for core executive posts, arguing that female leaders' intention to promote women's presence in office is hindered by the need to generate positive media coverage and reserve offices for male challengers (O'Brien et al. 2015). To ensure that the sex of the HoG does not confound our findings, we measured the variable sex of $\mathrm{HoG}$ based on our own data, indicating whether the minister served under a male or a female HoG at the end of our observation period (i.e., when reaching a highly prestigious position or leaving the government).

Second, the share of women in the lower chamber of the legislature (\% women in lower chamber) constitutes a key explanatory variable for women's presence in the cabinet. Given that ministers are frequently recruited from parliament, female representatives are the eligible candidates available to gatekeepers, and the numerical strength of women in parliament enhances the chance of selection for female ministers (Escobar-Lemmon and Taylor-Robinson 2005; Whitford, Wilkins, and Ball 2007, 563). Following this rationale, women's enhanced presence in the legislature should also make it more likely that the group includes women with substantial expertise in the most prestigious portfolios and should increase the speed with which women proceed to these positions. We use the share of women just before reaching a highly prestigious position or leaving the government from the V-Dem data to control for this phenomenon (Coppedge et al. 2019).

Following this logic, we also include a dummy variable for postcommunist countries, because these cases tend to display particularly low levels of women's representation (Hughes and Paxton 2019)

Furthermore, we control for the decade in which a person either reaches a highly prestigious position or leaves the government using decade dummies (1990-2000, 2000-2010, 2010-18), as women's role 
perception and representation changed over time (Hughes and Paxton 2019).

The models do not control for the political career characteristics of ministers before entering the executive, such as the time they spent in parliament or party offices, because there is no complete data set providing this information. However, we are confident that these variables do not induce omitted variable bias because there is no systematic evidence indicating that men tend to be better qualified when first entering the executive than women. Studies comparing the preparedness of male and female ministers produce mixed results depending on the type of political experience they take into account and the political system they study (Franceschet and Piscopo 2012; Murray 2010; O'Brien 2015; Verge and Astudillo 2018). In the context of European democracies, Verge and Astudillo (2018) find that female members of (regional) executives are even better equipped for the job than their male counterparts. Moreover, men and women who get to the top executive post $(\mathrm{HoG})$ display no systematic differences in their career paths (Baturo and Gray 2018; Müller-Rommel and Vercesi 2017).

\section{EMPIRICAL EVIDENCE FOR GENDERED CAREER PATHS TO PRESTIGIOUS MINISTERIAL POSITIONS}

Of the 1,912 ministers who succeeded in reaching a prestigious executive position, only 255 , or $13.34 \%$, are women. While $45.82 \%$ of all male ministers eventually get to the top, only $27.36 \%$ of female ministers have a similarly successful executive career. ${ }^{12}$ Figure 1 shows considerable variation at the country level in this regard: the Nordic countries display the highest number of women in prestigious positions, ranging from $39.22 \%$ in Norway to $25 \%$ in Denmark. At the other extreme, we find that Hungary has the lowest absolute number and relative share of women selected for highly prestigious executive offices during the last decades (2 or $3.57 \%$ ). Germany and Ireland follow with very low absolute numbers, even though the ratio of women to men is lower in Greece, Slovakia, Poland, and Portugal. ${ }^{13}$ Ministers succeeding in

12. This gender gap in appointment to highly prestigious positions is statistically significantly different from zero at the $0.001 \%$ level according to a $t$-test for mean comparison (see details in Appendix 2).

13. We account for these country-level differences by including a dummy for postcommunist countries in the main models, as well as through a series of robustness tests including a dummy variable for the Nordic countries and a model with country fixed effects (see Tests 5 and 8 in Appendix 5 and 7). 


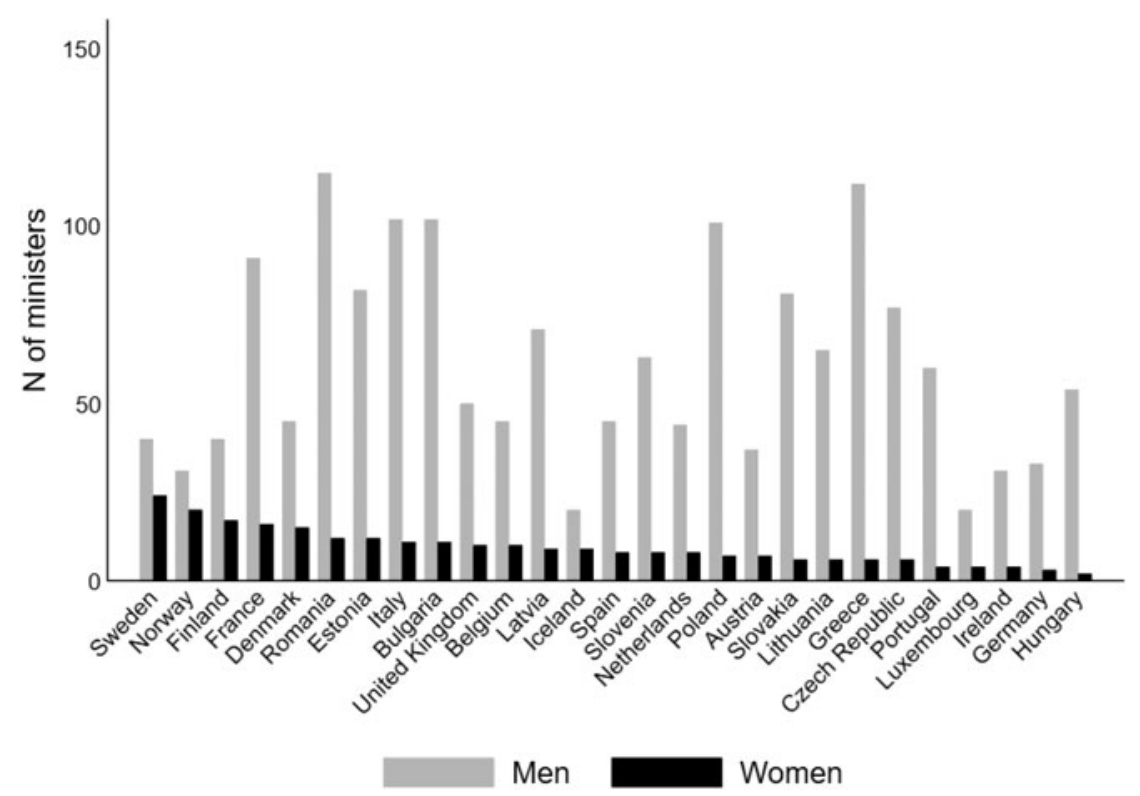

FIGURE 1. Number of ministers reaching prestigious positions per country by sex.

reaching a prestigious post require, on average, 5.88 months to get there. The speed to the top varies considerably, with a standard deviation of 15.12 months. Men tend to escalate to top positions twice as fast as women, with a mean duration in lower-prestige offices of 5.17 months compared to 10.53 months (with $p<.001$ according to a $t$-test for mean comparison, see Appendix 2 in the supplementary material online). ${ }^{14}$ Figure 2 shows how the odds of reaching a highly prestigious position change over time for men and women. Men are consistently more likely to be selected for a prestigious executive position. However, women who serve in less prestigious government positions for more than eight years suddenly experience steep increases in their chances of receiving a highly prestigious portfolio. This catch-up effect narrows the gap between men's and women's likelihood of promotion, and the confidence intervals of the two cumulative hazard functions start to overlap.

14. Notably, many ministers who receive highly prestigious portfolios are newcomers without any previous experience in government $(82.85 \%)$. However, the proportion of women ascending through different ministerial posts to highly prestigious positions is $50 \%$ higher than the proportion of women immediately receiving such a post (18.9\% compared to $12.2 \%)$. Studying the course of ministerial careers is therefore of particular interest to understand women's pathway to the most influential executive offices. 


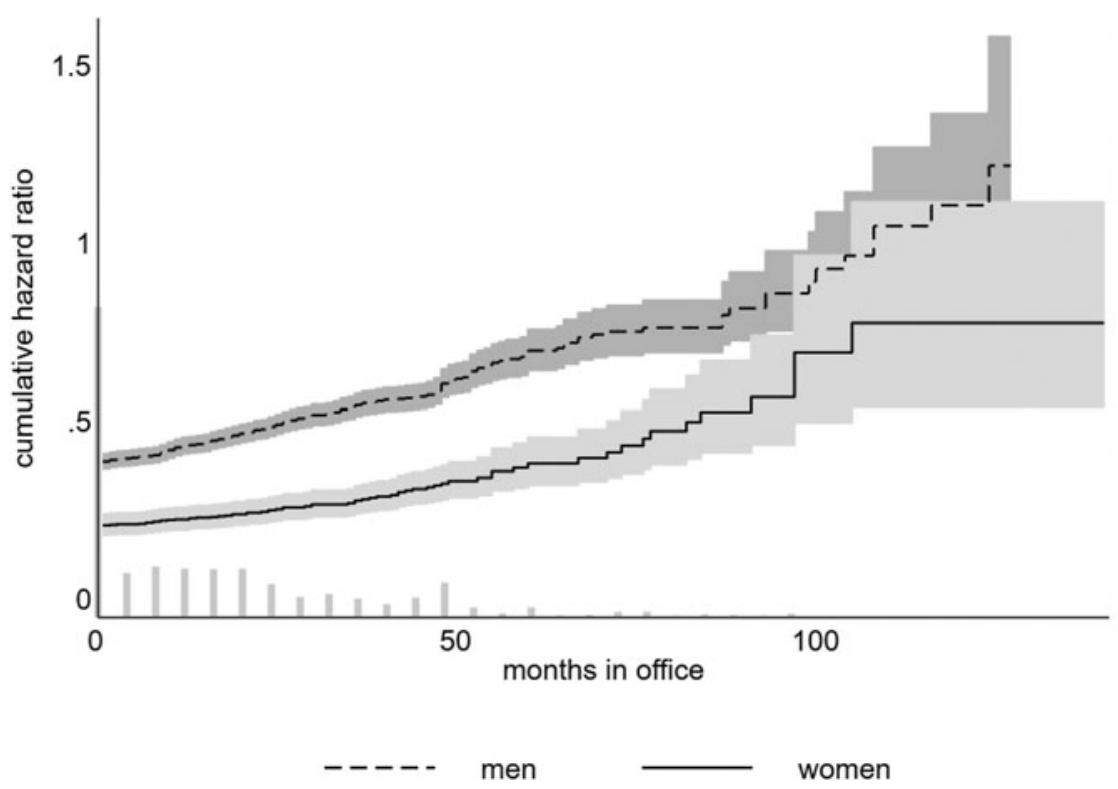

FIgURE 2. Nelson-Aalen cumulative hazard estimates for high-prestige offices by sex with 95\% confidence intervals. Bar graph shows frequency distribution of months in office before reaching a high-prestige office.

The multivariate analysis reveals the extent to which this pattern persists when taking other factors, in particular the gendered nature of the portfolio, into account. For that purpose, we apply survival analysis. We use a semi-parametric Cox model in which the baseline hazard rate is estimated from the data, since we have no theoretically grounded assumption about its shape (Golub 2008, 531). This model can work with censored data (Box-Steffensmeier and Jones 2004), making it possible to run a survival analysis even though the event "entrance into a prestigious position" did not (yet) occur for all individuals in our data set. We assume that the standard errors correlate at the country level, as some have more male or female ministers and different numbers of total ministers in government, hence they include clustered standard errors. As outlined in the robustness tests section, we ran a series of alternative modeling strategies and include additional variables, but neither of these changes modified the findings as described here.

Table 2 presents the results of Cox proportional hazard models. Model 1 presents the effects of the minister's sex and the gendered nature of the portfolio independently to test $\boldsymbol{H}_{\boldsymbol{1}}$ and $\boldsymbol{H}_{2}$. Model 2 additionally 
Table 2. Cox proportional hazard model for time in office before reaching a high-prestige portfolio

$\begin{array}{lc}\text { Model } 1 & \text { Model } 2 \\ \text { HR/ (SE) } & \text { HR/ (SE) }\end{array}$

\begin{tabular}{lll} 
Explanatory variables & & \\
Minister = woman & $0.726^{* * * *}$ & $0.724^{* * * *}$ \\
& $(0.040)$ & $(0.047)$ \\
Portfolio = feminine & $0.175^{* * * *}$ & $0.174^{* * * *}$ \\
& $(0.027)$ & $(0.030)$ \\
Minister = woman & & 1.017 \\
${ }^{*}$ Portfolio = feminine & & $(0.192)$ \\
& & \\
Control variables & 1.018 & 1.018 \\
HoG = woman & $(0.145)$ & $(0.145)$ \\
& 1.002 & 1.002 \\
\% women in lower chamber & $(0.002)$ & $(0.002)$ \\
Postcommunist country & 1.003 & 1.003 \\
& $(0.052)$ & $(0.052)$ \\
Decade = 2000-2009 & $0.895^{* *}$ & $0.895+$ \\
& $(0.050)$ & $(0.051)$ \\
Decade = 2010-2019 & $0.852^{* * *}$ & $0.852^{* * *}$ \\
& $(0.047)$ & $(0.047)$ \\
\hline Observations & 4,517 & 4,517 \\
N failures & $1,897.000$ & $1,897.000$ \\
Log-likelihood & $-15,133.410$ & $-15,133.406$ \\
\hline
\end{tabular}

Notes: Coefficients display hazard ratios; rounded hazard ratios of 1.000 have been rounded up to 1.001 or rounded down to 0.999 to signal the direction. All models include standard errors clustered at the country level. Since information on the share of women in parliament is missing for 31 cases, the number of observations decreases slightly.

* $p<.05 ; * * * 0<.01 ; *$ ***** $p<.001$.

includes an interaction effect between the two variables to study $\boldsymbol{H}_{3}$. The coefficients in our results show hazard ratios. A value below 1 indicates a decreasing hazard for promotion to a high-prestige position and increased duration in a low- or medium-prestige position. A value above 1, by contrast, indicates an increasing hazard for receiving a highly prestigious portfolio and shorter terms in less prestigious positions (George, Seals, and Aban 2014, 688-89).

The results lend robust support to our first hypothesis: minister's sex has an effect on the time spent in less prestigious positions before reaching a highly prestigious portfolio for the first time. If a minister is a woman instead of a man, the hazard ratio decreases by $27.4 \%$. The coefficient is 


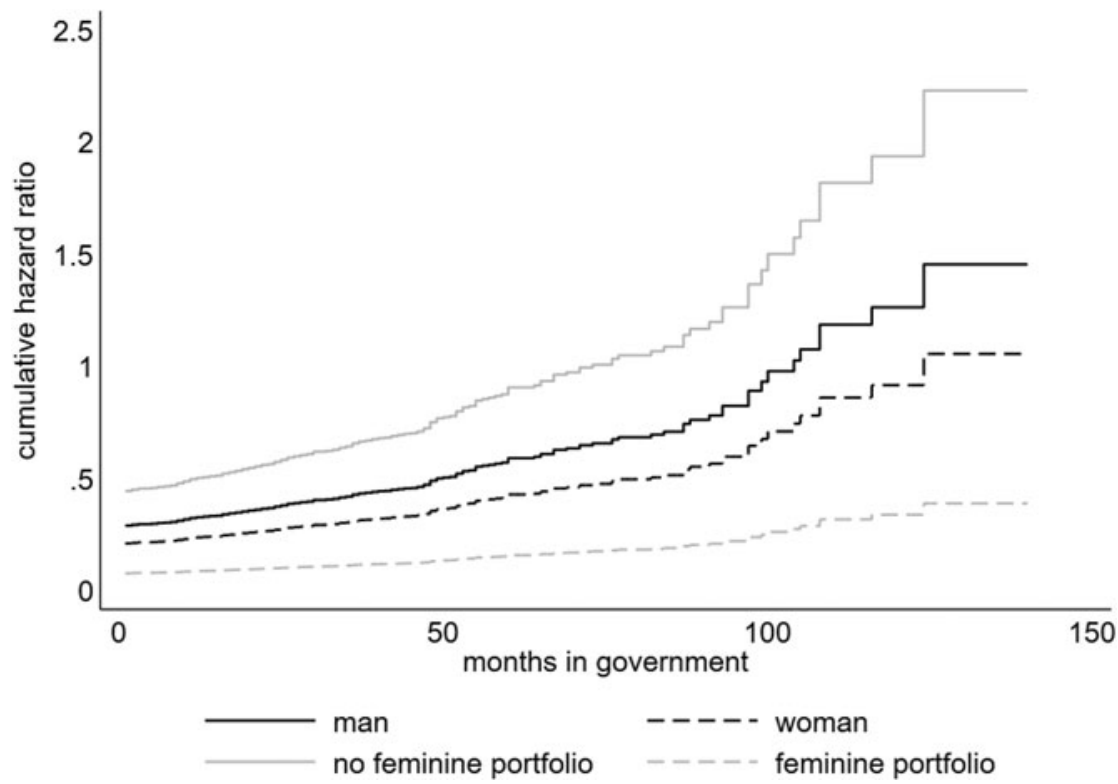

Figure 3. Cumulative hazard function of the likelihood to reach a high-prestige position over time by sex and gendered nature of portfolio. Based on Model 1 in Table 2.

statistically significantly different from 0 at the $0.1 \%$ level. Figure 3 displays this effect visually over time. The solid black line indicates the chances that a female minister has received a highly prestigious portfolio after a given number of months in office; the solid gray line indicates the same value for a male minister, all else being equal. After having spent the same amount of time in a less prestigious position, the chances for women to escalate to a prestigious post are consistently lower than for men. Nevertheless, we observe that spending time in other positions increases the chances of eventually moving to a desired prestigious post. As a consequence, and as suggested by $\boldsymbol{H}_{\boldsymbol{l}}$, female ministers need to serve longer in less prestigious positions before having equal chances of promotion as their male colleagues.

The analyses also confirm our second proposition: holding a portfolio that is typically associated with feminine stereotypes decreases the hazard ratio for reaching a highly prestigious position by $84 \%$ (as opposed to a position associated with masculine traits or without such an ascription to any gender). Assuming responsibility for portfolios such as family, children, elderly, health, or social affairs hence extends the time it takes 
for a minister - independent of their sex - to get to the top executive positions. Figure 3 reveals how this effect unfolds over time by showing the cumulative hazard function for ministers that held a feminine ministry (black dashed line) and those who did not (gray dashed line). For those ministers who never held a feminine portfolio, the cumulative hazard ratio increases steeply as time proceeds. For their colleagues serving in these positions, the chances of reaching a highly prestigious position are extremely low and barely increase over time.

Despite this strong support for our first and second proposition, we do not find any evidence for the expectation that being a woman in a feminine ministry creates a double barrier, as suggested by $\boldsymbol{H}_{3}$. The interaction term presented in Model 2 in Table 2 is not statistically significantly different from zero.

To test the robustness of our findings, we ran a series of tests considering time-dependent hazard ratios, potential selection bias in our sample, and omitted variable bias, as well as validity concerns regarding the operationalization of the dependent variable. To begin with, we acknowledge that hazards might vary over time for different observations (Box-Steffensmeier and Jones 2004). The proportional hazard test reveals that minister's sex, the gendered nature of the portfolio, the HoG's sex, and the share of women in parliament violate this assumption in most models. To overcome this problem, we interact these variables with the natural logarithm of time, as suggested by Box-Steffensmeier and Zorn (2001) (Test 1).

Furthermore, we test for potential selection bias in the sample. In this series of tests, we excluded ministers who received a highly prestigious office as their first executive post. Only $17.15 \%$ of all ministers reaching highly prestigious positions previously held other portfolios. Different logics might apply for those recruited immediately to the most influential positions and those recruited later (Test 2). Additionally, in light of the strong decade effects in Models 1 and 2, we reduced our sample to ministers who either reached a highly prestigious post in 2010 or later and those who held their last office without proceeding to a prestigious position in 2010 or later. As the acceptance of women's engagement in politics and in the executive increased over time, the effects of a minister's sex and the gendered nature of the portfolio might have disappeared in more recent years (Test 3).

As a third kind of robustness test, we control for omitted variable bias. As part of these tests, we added party-level factors: the ideology of the party on a right-left scale and party size in parliament. Left-wing parties tend to 
present themselves as advocates of a feminist culture and more often adopt party quotas promoting women's presence in politics, which indirectly increases women's chances of receiving a masculine portfolio of high status (Goddard 2019a). We used the left-right index from the Comparative Manifestos Project (Volkens et al. 2019). Governing parties in our sample range from -45.418 (left) to 90.909 (right). As a second party-level variable, we take party strength in parliament into account. This factor serves as a proxy for the number of government seats that the minister's party might fill; higher numbers of appointments should be associated with better chances for women to enter government (Goddard $2019 b$ ) or proceed to highly prestigious positions (Test 4). ${ }^{15}$

We also consider the option of omitted variable bias at the country level. For that purpose, we include a dummy variable for the Nordic countries, which are well known to provide better career opportunities for women in politics (Test 5). Moreover, we take alternative operationalizations for the pool of female aspirants into account, first by including a measure for the (mean) share of women in female ministries in the cabinet $(\%$ women in cabinet). For this purpose, we calculated the number of female ministers in feminine domains per government and measured the share by using the total number of ministers of each government (Test 6). A second alternative operationalization for country-level differences in the share of eligible female aspirants is the existence of a national-level gender quota for the lower chamber of the legislature (Claveria 2014; Goddard 2019a, 636). We use an ordinal scaled variable that takes a value of 0 if a country did not have a quota arrangement, 1 for quotas without sanctions, 2 for quotas with weak sanctions, and 3 for quotas with strong sanctions (data from Coppedge et al. 2019) (Test 7). Moreover, we consider that particularly in coalition governments, who leads a party might be just as decisive for ministerial appointments as who leads the government (O'Brien et al. 2015).

Because of a lack of complete data on the sex of party leaders in coalition governments, we address the biasing effect that the sex of the party leader might have for our findings through two additional tests. First, we merged our data with information on the sex of party leaders compiled by O'Brien (2015), which allows us to test the robustness of our evidence for a subsample of 548 ministers from six countries while taking this

15. Given that many ministers are independent $(N=761)$ or belong to (minor) parties not included in the MARPOR data set $(N=940)$, the sample size decreases for this test, but the findings are robust to this modification. 
additional confounder into account (Test 8). Second, we limit our sample to single-party governments to see whether the observed patterns hold for cases without potential confounding influence of coalition partners. This test allows us to study 905 ministers in 15 countries (Test 9).

Beyond these party-level factors, the chances for women to ascend to top positions might also be limited by the number of seats their party occupies in a coalition government (Krook and O'Brien 2012). To take the scarcity of offices into account, we created a variable counting the number of appointments per party within a cabinet (excluding independent ministers) and introduced this measure into the model in Test 10 . Moreover, we consider unobserved country-level factors, such as differences in the requirement to recruit ministers from parliament, investiture votes, or executive term limits by including country fixed effects (Test 11).

Lastly, we test whether the inclusive definition of prestigious portfolios biases the findings. In particular, it is possible that the interaction between the sex of ministers and the gendered nature of portfolios only plays out for the core portfolios (i.e., foreign affairs, finance, economy, interior, and defense). For Test 12, we recoded the level of prestige and recalculated time in office in accordance with such a restrictive definition of highly prestigious posts.

The results of all tests are presented in Appendices 3-8. None of the modifications outlined here changes the results presented in the text. All models lead us to reject $\boldsymbol{H}_{3}$, while lending support for $\boldsymbol{H}_{\mathbf{l}}$ and $\boldsymbol{H}_{2}$.

\section{CONCLUSION}

This article made use of event history analysis to uncover latent gender bias in the career paths of ministers after initial selection to the cabinet. Looking at original data on ministers' career paths in 27 European countries between 1990 and 2018, we showed that the journey to prestigious positions looks different for men and for women: male ministers tend to receive the most well resourced and influential portfolios either without previous executive experience or shortly after being selected to cabinet, while their female colleagues have to wait considerably longer to get to the top. This finding implies that women, even after overcoming initial barriers for ministerial selection, do not have the same career prospects as men. Furthermore, we showed that the set of portfolios that can be labeled feminine, because they include responsibilities that are assigned 
to women according to stereotypes about traditional roles in society, are particularly poor career stepping stones for all ministers. Yet, contrary to our original anticipation, being in charge of portfolios such as family, children, elderly, health, or social affairs does not create additional barriers for women compared with men.

Going beyond previous research highlighting that women stand low chances of being selected for masculine and highly prestigious ministerial positions (Escobar-Lemmon and Taylor-Robinson 2009; Goddard 2019a; Krook and O'Brien 2012), the findings presented here help us understand how this pattern emerges. To begin with, female aspirants often reach prestigious offices after they have served in other positions for extensive periods. We argued that these patterns indicate that between their initial selection to the cabinet and promotion to a high-profile portfolio, they have to prove competencies that are often taken for granted among their male colleagues and/or have to gather more extensive experience than men to be considered sufficiently qualified candidates for the most influential executive posts. Moreover, our findings suggest that the type of ministerial experience a woman is most likely to have is valued the least by gatekeepers. Assuming responsibility for a feminine portfolio constitutes a dead end for the careers of both male and female politicians - but women's executive careers are considerably more likely to end up taking such a turn. An interesting endeavor for future research will be to study the causal mechanisms behind these patterns. Similar to the study on ministerial appointments conducted by Annesley, Beckwith, and Franceschet (2019), in-depth interviews with party gatekeepers will allow researchers to uncover why certain ministers remain longer in less prestigious posts before ascending to the top. In particular, such work could shed light on the role of women's perceived experience by gatekeepers as opposed to their actual experience in the executive.

The insights presented in this study also provide additional evidence that despite of women's increasing access to political offices (Franceschet, Krook, and Tan 2019), the political careers of men and women continue to look very different. Women who become prime ministers are usually more qualified and have distinct political careers compared with men (Müller-Rommel and Vercesi 2017), and women party leaders have to perform particularly successfully to remain in office (O'Brien 2015). The career paths through which predominantly men tend to enter parliament are more likely to lead to a ministerial position than the career choices of women members of parliament (Ohmura et al. 2018). 
Moreover, women need higher qualifications with more working experience in general and in the portfolio itself than men to be recruited for a ministerial position (Escobar-Lemmon and Taylor-Robinson 2009, 693). We add to this story by showing that women ministers are often sidelined for long periods in secondary portfolios with less prestige. A pattern hence emerges, suggesting that barriers to women's equal inclusion into politics are becoming subtler and more complex. A systematic study of the strategies applied by gatekeepers to do so would be another timely contribution to the literature.

Corinna Kroeber is Assistant Professor of Comparative Politics at the University of Greifswald: Corinna.Kroeber@uni-greifswald.de; Joanna Hüffelmann is graduate student at the University of Greifswald: Joanna. Hueffelmann@stud.uni-greifswald.de

\section{SUPPLEMENTARY MATERIAL}

To view supplementary material for this article, please visit https:/doi.org/ 10.1017/S1743923X21000118.

\section{REFERENCES}

Andersson, Staffan, Torbjörn Bergman, and Svante Ersson. 2014. "European Representative Democracy (ERD), Release 3.0 February 12, 2014, Codebook for ERD - e.” https://erdda. se/datafiles/erd/2014/ERD\%20-\%20e\%20Codebook\%20Release\%203\%20February\% 2012\%202014.pdf (accessed March 15, 2018).

Annesley, Claire, Karen Beckwith, and Susan Franceschet. 2019. Cabinets, Ministers, and Gender. Oxford: Oxford University Press.

Annesley, Claire, and Francesca Gains. 2010. "The Core Executive: Gender, Power and Change." Political Studies 58 (5): 909-29.

Arriola, Leonarda R., and Martha C. Johnson. 2014. "Ethnic Politics and Women's Empowerment in Africa: Ministerial Appointments to Executive Cabinets." American Journal of Political Science 58 (2): 495-510.

Barnes, Tiffany D., and Diana Z. O'Brien. 2018. "Defending the Realm: The Appointment of Female Defense Ministers Worldwide.” American Journal of Political Science 62 (2): 355-68.

Barnes, Tiffany D., and Michelle M. Taylor-Robinson. 2018. "Women Cabinet Ministers in Highly Visible Posts and Empowerment of Women: Are the Two Related?" In Measuring Women's Political Empowerment across the Globe: Strategies, Challenges, and Future Research, eds. Amy C. Alexander, Catherine Bolzendahl, and Farida Jalalzai. London: Palgrave Macmillan, 229-56.

Baturo, Alexander. 2017. "Democracy, Development, and Career Trajectories of Former Political Leaders.” Comparative Political Studies 50 (8): 1023-54.

Baturo, Alexander, and Julia Gray. 2018. "When Do Family Ties Matter? The Duration of Female Suffrage and Women's Path to High Political Office." Political Research Quarterly 71 (3): 695-709. 
Berlinski, Samuel, Torun Dewan, and Keith Dowding. 2007. "The Determinants of Ministerial Tenure in the United Kingdom, 1945-1997." British Journal of Political Science 37 (2): 245-62.

Box-Steffensmeier, Janet M., and Bradford S. Jones. 2004. Event History Modeling: A Guide for Social Scientists. Cambridge: Cambridge University Press.

Box-Steffensmeier, Janet M., and Christopher J. W. Zorn. 2001. "Duration Models and Proportional Hazards in Political Science." American Journal of Political Science 45 (4): 972-88.

Bright, Jonathan, Holger Döring, and Conor Little. 2015. "Ministerial Importance and Survival in Government: Tough at the Top?" West European Politics 38 (3): 441-64.

Broverman, Inge K., Susan Raymond Vogel, Donald M. Broverman, Frank E. Clarkson, and Paul S. Rosenkrantz. 1972. "Sex-Role Stereotypes: A Current Appraisal.: Journal of Social Issues 28 (2): 59-78.

Burrell, Barbara C. 1994. AWoman's Place Is in the House: Campaigning for Congress in the Feminist Era. Ann Arbor: University of Michigan Press.

Carli, Linda L. 2001. "Gender and Social Influence." Journal of Social Issues 57 (4): 725-41.

Claveria, Sílvia. 2014. “Still a 'Male Business'? Explaining Women’s Presence in Executive Office." West European Politics 35 (5): 1156-76.

Claveria, Sílvia, and Tània Verge. 2015. "Post-Ministerial Occupation in Advanced Industrial Democracies: Ambition, Individual Resources and Institutional Opportunity Structures." European Journal of Political Research 54 (4): 819-35.

Coppedge, M., et al. 2019. "V-Dem Codebook v9, Varieties of Democracy (V-Dem) Project." https://www.v-dem.net/media/filer_public/e6/d2/e6d27595-9d69-4312-b09f63d2a0a65df2/v-dem_codebook_v9.pdf.

Costa Pinto, António, and Pedro Tavares de Almeida. 2009. "Portugal: The Primacy of 'Independents." In The Selection of Ministers in Europe: Hiring and Firing, eds. Keith Dowding and Patrick Dumont. London: Routledge, 147-58.

Dörrenbächer, Nora. 2016. "Patterns of Post-Cabinet Careers: When One Door Closes Another Door Opens?" Acta Politica 51 (4): 472-91.

Eagly, Alice H., and Steven J. Karau. 2002. "Role Congruity Theory of Prejudice toward Female Leaders." Psychological Review 109 (3): 573-98.

Eagly, Alice H., and Antonio Mladinic. 1989. "Gender Stereotypes and Attitudes toward Women and Men." Personality and Social Psychology Bulletin 15 (4): 543-58.

_ 1994. "Are People Prejudiced against Women? Some Answers from Research on Attitudes, Gender Stereotypes, and Judgments of Competence." European Review of Social Psychology 5 (1): 1-35.

Eagly, Alice H., Christa Nater, David I. Miller, Michèle Kaufmann, and Sabine Sczesny. 2020. "Gender Stereotypes Have Changed: A Cross-Temporal Meta-Analysis of U.S. Public Opinion Polls from 1946 to 2018.” American Psychologist 75 (3): 301-15.

Escobar-Lemmon, Maria, and Michelle M. Taylor-Robinson. 2005. "Women Ministers in Latin American Government: When, Where and Why?" American Journal of Political Science 49 (4): 829-44.

_ 2009. "Getting to the Top: Carrier Paths of Women in Latin American Cabinets." Political Research Quarterly 62 (4): 685-99.

Escobar-Lemmon, Maria C., and Michelle M. Taylor-Robinson. 2016. Women in Presidential Cabinets: Power Players or Abundant Tokens?. New York: Oxford University Press.

Franceschet, Susan. 2016. "Disrupting Informal Institutions? Cabinet Formation in Chile in 2006 and 2014." In Gender, Institutions, and Change in Bachelet's Chile, ed. Georgina Waylen. New York: Palgrave Macmillan, 67-94.

Franceschet, Susan, Mona Lena Krook, and Jennifer M. Piscopo. 2012. "Themes and Implications for Future Research on Gender Quotas.” In The Impact of Gender 
Quotas, eds. Susan Franceschet, Mona Lena Krook, and Jennifer M. Piscopo. New York: Oxford University Press, 229-43.

Franceschet, Susan, Mona Lena Krook, and Netina Tan, eds. 2019. The Palgrave Handbook of Women's Political Rights. London: Palgrave Macmillan.

Franceschet, Susan, and Jennifer M. Piscopo. 2012. "Gender Quotas and Political Backgrounds in Argentina." In The Impact of Gender Quotas, eds. Susan Franceschet, Mona Lena Krook, and Jennifer M. Piscopo. New York: Oxford University Press, 43-56.

_ . 2014. "Sustaining Gendered Practices? Power and Elite Networks in Argentina." Comparative Political Studies 47 (1): 85-110.

George, Brandon, Samantha Seals, and Inmaculada Aban. 2014. "Survival Analysis and Regression Models." Journal of Nuclear Cardiology 21 (4): 686-94.

Goddard, Dee. 2019a. "Entering the Men's Domain? Gender and Portfolio Allocation in European Governments.” European Journal of Political Research 58 (2): 631-55.

_ 2019b. "Examining the Appointment of Women to Ministerial Positions across Europe: 1970-2015.” Party Politics. Published online October 18. https://doi.org/l0. $1177 / 1354068819878665$.

Golub, Jonathan. 2008. "Survival Analysis." In The Oxford Handbook of Political Methodology, Janet M. Box-Steffensmeier, Henry E. Brady and David. Collier. Oxford: Oxford University Press, 530-46.

Hoffman, Curt, and Nancy Hurst. 1990. "Gender Stereotypes: Perception or Rationalization?” Journal of Personality and Social Psychology 58 (2): 197-208.

Huber, John D., and Cecelia Martinez-Gallardo. 2008. "Replacing Cabinet Ministers: Patterns of Ministerial Stability in Parliamentary Democracies." American Political Science Review 102 (2): 169-80.

Hughes, Melanie M., and Pamela Paxton. 2019. “The Political Representation of Women over Time.” In The Palgrave Handbook of Women's Political Rights, eds. Susan Franceschet, Mona Lena Krook, and Netina Tan. London: Palgrave Macmillan, 33-51.

Jalalzai, Farida. 2008. "Women Rule: Shattering the Executive Glass Ceiling." Politics \& Gender 4 (2): 1-27.

2013. Shattered, Cracked, or Firmly Intact? Women and the Executive Glass Ceiling Worldwide. New York: Oxford University Press.

—. 2019. "Women Executives: Empowering Women through Selection in Germany and Brazil." In Elites and People: Challenges to Democracy, eds. Fredrik Engelstad, Trygve Gulbrandsen, Marte Mangset, and Mari Teigen. Bingley: Emerald Publishing Limited, 159-86.

Kenney, Sally J. 1996. "New Research on Gendered Political Institutions." Political Research Quarterly 49 (2): 445-66.

Kerby, Matthew, and Feodor Snagovsky. 2019. "Not All Experience Is Created Equal: MP Career Typologies and Ministerial Appointments in the Canadian House of Commons, 1968-2015." Government and Opposition. Published online November 6. https://doi. org/10.1017/gov.2019.29.

Krook, Mona Lena, and Diana Z. O’Brien. 2012. "All the President's Men? The Appointment of Female Cabinet Ministers Worldwide." Journal of Politics 74 (3): 840-55.

Lawless, Jennifer L. 2012. Becoming a Candidate: Political Ambition and the Decision to Run for Office. Cambridge: Cambridge University Press.

Lyness, Karen S., and Donna E. Thompson. 2000. "Climbing the Corporate Ladder: Do Female and Male Executives Follow the Same Route?" Journal of Applied Psychology 85 (1): 86-101.

Müller-Rommel, Ferdinand, and Michelangelo Vercesi. 2017. "Prime Ministerial Careers in the European Union: Does Gender Make a Difference?" European Politics and Society 18 (2): 245-62. 
Murray, Rainbow. 2010. "Second among Unequals: A Study of Whether France's 'Quota Women' Are Up to the Job." Politics \& Gender 6 (1): 93-1 18.

Niven, David. 1998. "Party Elites and Women Candidates: The Shape of Bias." Women \& Politics 19 (2): 57-80.

O'Brien, Diana Z. 2015. "Rising to the Top: Gender, Political Performance, and Party Leadership in Parliamentary Democracies." American Journal of Political Science 59 (4): 1022-39.

O’Brien, Diana Z., Matthew Mendez, Jordan Carr Peterson, and Jihyun Shin. 2015. "Letting Down the Ladder or Shutting the Door: Female Prime Ministers, Party Leaders, and Cabinet Ministers." Politics \& Gender 11 (4): 689-717.

Ohmura, Tamaki, Stefanie Bailer, Peter Meißner, and Peter Selb. 2018. "Party Animals, Career Changers and Other Pathways into Parliament." West European Politics 41 (1): 169-95.

Rosenwasser, Shirley Miller, and Norma G. Dean. 1989. “Gender Role and Political Office: Effects of Perceived Masculinity/Femininity of Candidate and Political Office." Psychology of Women Quarterly 13 (1): 77-85.

Rüdel, Nils. 2019. "Andrea Nahles spricht in Maria Laach über Rücktritt." General Anzeiger, August 9. https://www.general-anzeiger-bonn.de/andrea-nahles-spricht-inmaria-laach-ueber-ruecktritt_aid-45054179 (accessed March 10, 2021).

Schlesinger, Joseph A. 1966. Ambition and Politics: Political Careers in the United States. Chicago: Rand McNally.

Schneider, Monica C., and Angela L. Bos. 2014. "Measuring Stereotypes of Female Politicians.” Political Psychology 35 (2): 245-66.

Siaroff, Alan. 2000. "Women's Representation in Legislatures and Cabinets in Industrial Democracies." International Political Science Review 21 (2): 197-215.

Verge, Tània, and Javier Astudillo. 2018. "The Gender Politics of Executive Candidate Selection and Reselection." European Journal of Political Research 58 (2): 720-40.

Verge, Tània, and Sílvia Claveria. 2017. "Party Office, Male Homosocial Capital and Gendered Political Recruitment." In Gender and Informal Institutions, ed. Georgina Waylen. Lanham, MD: Rowman \& Littlefield, 91-114.

Verge, Tània, and Maria de la Fuente. 2014. "Playing with Different Cards: Party Politics, Gender Quotas and Women's Empowerment." International Political Science Review 35 (1): 67-79.

Volkens, Andrea, Werner Krause, Pola Lehmann, Theres Matthieß, Nicolas Merz, Sven Regel, and Bernhard Weßels. 2019. "The Manifesto Project Main Dataset (MRG/CMP/MARPOR).” Version 2019b. https:/doi.org/10.25522/manifesto.mpds. 2019b.

Warwick, Paul V., and James N. Druckman. 2006. "The Portfolio Allocation Paradox." European Journal of Political Research 45 (4): 635-65.

Whitford, Andrew, Vicky Wilkins, and Mercedes G. Ball. 2007. "Descriptive Representation and Policymaking Authority: Evidence from Women in Cabinets and Bureaucracies." Governance 20 (4): 559-80.

Yuval-Davis, Nira. 1997. "Women, Citizenship and Difference." Feminist Review 57 (1): 4-27. 